\title{
Biomechanics of the Craniovertebral Junction
}

\author{
Jeffrey G. Clark, Kalil G. Abdullah, \\ Thomas E. Mroz and Michael P. Steinmetz \\ Cleveland Clinic \\ United States of America
}

\section{Introduction}

The craniovertebral junction (CVJ) consists of the occiput and the first two cervical vertebrae, and functions as an articulation point capable of complex motions distinct from the remainder of the spinal column. These unique features make the CVJ more mobile than any of the other joints in the cervical spinal column, and important biomechanical properties must be understood in order to properly accommodate instrumentation to stabilize the spine after trauma, neoplasm, or degenerative disease. Each joint (Occiput-C1 and C1-C2) has its own unique biomechanical properties; at the occiput-C1 joint, bony structures are most responsible for stability and motion, while at the C1-C2 joint, ligamentous structures provide greater stability and motion compared to the bony elements.

A fundamental understanding of the biomechanics of the CVJ is important for spinal surgeons, physical therapists, and biomechanical engineers. In this chapter, we will review basic biomechanical and physiological properties of the CVJ, and then discuss common changes in biomechanics that occur via trauma and degenerative disease. This will provide the foundation for a brief discussion on techniques for the fixation of the craniovertebral junction.

\section{Anatomy}

The biomechanical features of the CVJ arise from the unique characteristics of the structures that comprise this region. It is first important to examine the osteology, joints, ligamentous structures, and blood supply that make up the CVJ.

\subsection{Osteology}

The osteology of the CVJ consists of three unique bones: the occiput, atlas (C1), and axis (C2). The occiput is the most inferior bone of the skull. The atlas and axis are the first and second cervical vertebrae, respectively.

The occiput is a thin bone that contributes to the calvaria and base of the skull. Its posterior surface is firmly attached to the parietal bones through the lamboid suture. Its lateral surfaces are attached to the temporal bones through the occipitomastoid sutures. Anteriorly, the occiput is attached to the sphenoid bone. On the posterior surface, a large, vertically oriented protuberance projects outwards, which at its highest point is referred to as the inion, which forms the attachment of the ligamentum nuchae. The occiput is especially 
notable for a large, triangular shaped hole in its inferior surface known as the foramen magnum, through which the brainstem and spinal cord connect at the cervicomedullary junction. A pair of occipital condyles lie anterolateral to the foramen magnum, and constitute the articulation points for the atlas. These articulation points are relatively flat, which limits the axial rotation of the atlanto-occipital joint.

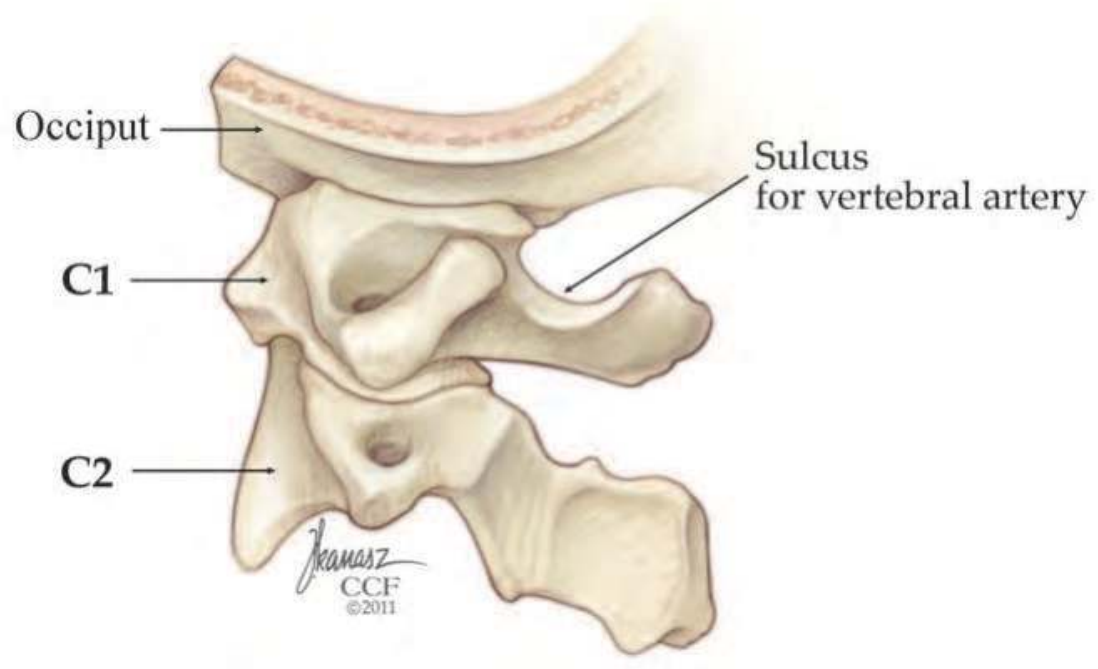

Fig. 1. Sagittal view of the occiput, atlas, and axis.

The atlas is ring-shaped, and contains two upward projecting lateral masses. These lateral masses articulate superiorly with the occipital condyles, forming the atlanto-occipital joint. Inferiorly, they form the atlanto-axial joint by articulating with the superior articular process of the axis. Through these two joints, they form a bridge between occiput and axis. The lateral masses are connected to each other by an anterior and a posterior arch that form a round outline to the spinal canal. The anterior arch is thinner than the posterior arch and is remarkable for a smoothed articulation point that is opposed to the odontoid process of the axis. In a small number of patients, the posterior arch may have a small cleft or rarely, it may have partial or complete aplasia (Gehweiler et al., 1983). The atlas does not have a vertebral body, as the embryological body becomes the odontoid process (dens) of the axis. Consequently, no intervertebral disk exists between the atlas and the axis. Transverse processes protrude horizontally from both sides of the atlas, and they extend more laterally than the transverse processes of the other cervical vertebrae. The foramen transversaria pierce these processes and create a channel through which the vertebral artery flows.

The axis is thicker and narrower than the atlas. On the anterior side, the vertebral body is flanked by two lateral masses. The odontoid process protrudes upwards from the center of the body to articulate with the posterior arch of the atlas, forming the key articulation point for axial rotation of the cervical spine. The lateral masses articulate superiorly with the inferior articular processes of the atlas. The vertebral arch defines the posterior borders of the vertebrae, and encloses a triangular-shaped spinal canal. On the inferior surface of the 
vertebral arch, the inferior articular processes of the axis protrude downward and articulate with the superior articular processes of C3. These are located posterior to the superior articular processes of the axis, approximately equidistant from the anterior and posterior portions of the bone. Small transverse processes protrude laterally from between the articular processes and contain transverse foramen. The lamina and spinous process constitute the remainder of the vertebral arch. The spinous process is often, but not always, bifid (Martin et al., 2010).

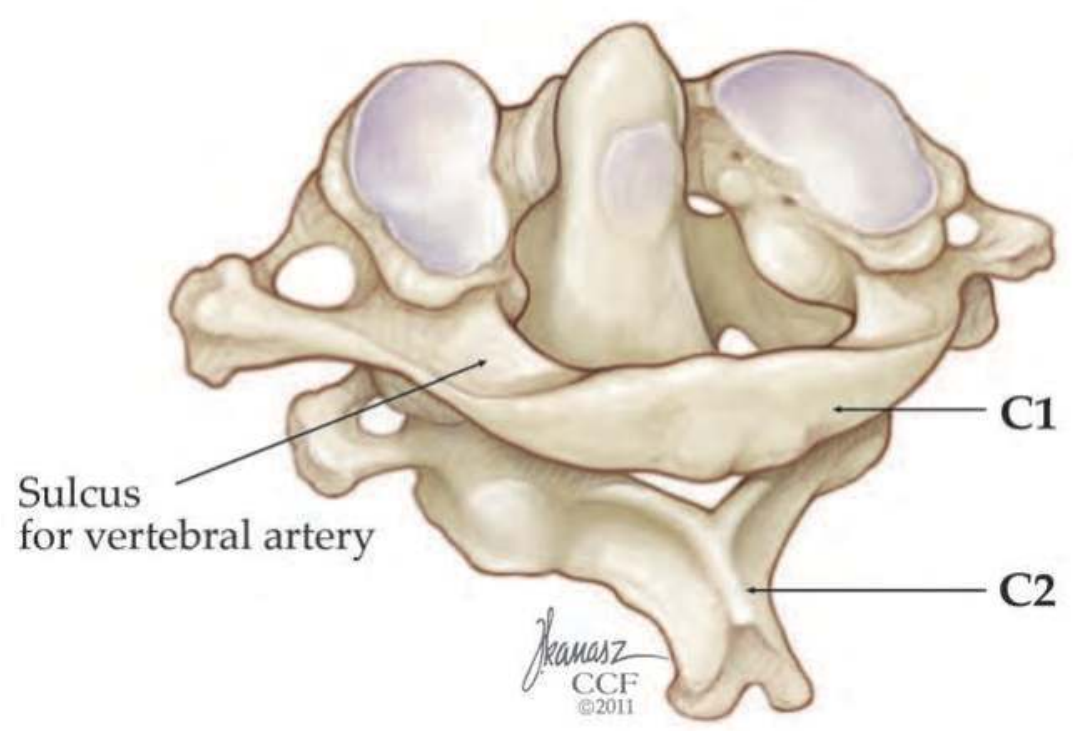

Fig. 2. Articulation between the atlas and the axis.

\subsection{Joints}

The CVJ consists of two synovial joints: the atlanto-occipital joint and the atlanto-axial joint. Each of these joints has unique anatomical and functional characteristics that contribute to the complex motion of the CVJ.

The atlanto-occipital joint is formed from articulation between the occipital condyles and the superior articular processes of the atlas. The articular processes of this joint are flat, which limits axial rotation and stabilizes flexion and extension. Each articulation forms a synovial joint surrounded by capsular ligaments.

The atlanto-axial joint has two distinct articulation points that act together to enable axial rotation. The first is a set of lateral articulations that are formed between the inferior articular processes of the atlas and the superior articular processes of the axis. The second set of articulations is formed between the odontoid process of the axis and the anterior arch of the atlas. The odontoid process functions as a pivot, and the lateral articulations permit ample rotation. Unlike the relatively flattened articular surfaces of the atlanto-occipital joint, the articular processes of the atlanto-axial joint are biconcave (Swartz et al., 2005). Loose and thin capsular joint ligaments surround the articulations in the CVJ complex, permitting a wide range of motion (Debernardi et al., 2011). 


\subsection{Ligamentous structures}

Eight main ligaments support the CVJ: the tectorial membrane, the alar ligament, the cruciate ligament, the apical ligament, capsular joints, accessory atlantoaxial ligament, and the anterior and posterior atlanto-occipital membranes (Debernardi et al., 2011).

The tectorial membrane is a longitudinal ligament that begins inferiorly as part of the posterior longitudinal ligament of the vertebral column and extends upward to become continuous with the cranial dura mater. It was initially thought that the tectorial membrane functioned to limit extension of the CVJ. However, more recent evidence suggests that the tectorial membrane prevents anterior spinal cord compression by the odontoid process (Tubbs et al., 2007).

The alar ligament is shaped like a flattened $\mathrm{V}$ and connects the anterior and superior portion of the odontoid process to the lateral masses of the atlas and to the occiput. (Debernardi et al., 2011). It functions to limit axial rotation of the atlanto-axial joint (Dvorak \& Panjabi, 1987).

The cruciate ligament is a thick, cross-shaped ligament with vertical and transverse components. The vertical component travels from the body of the axis to the clivus, while the transverse component (also called the transverse atlantal ligament or transverse ligament) extends from the medial side of the lateral masses of the axis and encloses the articulation formed between the odontoid process and the anterior arch of the atlas. The transverse portion of the cruciate ligament functions as an anatomical seatbelt, pulling the odontoid process tight against its articulation surface on the atlas. The transverse ligament also limits flexion of the CVJ (Debernardi et al., 2011; Panjabi et al., 1991c).

The apical ligament runs between the vertical portion of the cruciate ligament and the anterior atlanto-occipital membrane, connecting the anterior rim of the foramen magnum to the tip of the odontoid process. Some studies suggest that it may be congenitally absent in up to $20 \%$ of patients (Tubbs et al., 2000).

The capsular joints enclose the articulations between the occipital condyles and superior articular processes of the atlas, and between the inferior articular processes of the atlas and the superior articular processes of the axis. They also enclose the synovial fluid surrounding the joint and function to limit axial rotation in both joints of the CVJ (Debernardi et al., 2011).

The accessory atlantoaxial ligament connects the body of the axis to the lateral masses of the atlas and then continues cephalad to the occipital bone. In the past, this ligament was thought to be part of the tectorial membrane. However, studies now show that the fibers of these two ligaments are discontinuous (Tubbs et al., 2004). This ligament appears to check the rotation of both CVJ joints. However, its role in preventing hyperrotation is secondary to the function of the alar ligaments (Brolin \& Halldin, 2004; Debernardi et al., 2011).

The anterior and posterior atlanto-occipital membranes travel downward to connect the anterior and posterior rims of the foramen magnum to the anterior and posterior arches of the atlas. These ligaments, however, do not appear to be an important contributor to biomechanical stability of the CVJ (Debernardi et al., 2011).

\subsection{Blood supply}

Blood is principally supplied to the CVJ through branches from the vertebral arteries. The vertebral arteries arise from the subclavian arteries and travel superiorly through the transverse foramen of the cervical spinal column. Upon leaving the transverse foramen of 
C2, the vertebral artery is only minimally protected by dorsal bony structures as compared to when the artery runs through the subaxial spine. It also travels laterally to tunnel through the more lateral transverse foramen of the atlas. Upon leaving the atlas, the vertebral artery turns medially and pierces through the posterior ligaments and dura before ascending through the foramen magnum. As these arteries approach the alar ligament, they anastomose with the apical arcade that surrounds the odontoid process. Because the odontoid process is attached to the body of the axis by a cartilaginous plate, no vascular communication occurs between these portions of the axis (Menezes \& Traynelis, 2008).

\section{Normal biomechanics}

The CVJ plays an important role in the overall motion of the cervical spine, accounting for $25 \%$ of the flexion and extension and up to $50 \%$ of the axial rotation of the neck (Menezes \& Traynelis, 2008). Although the CVJ consists of two distinct joints (atlanto-occipital and atlanto-axial), it still functions as a single mobile unit, with the atlas acting like a washer between the cervical spine and the occiput. Each of these joints, however, has unique kinematic properties that contribute to the complex motion of the CVJ.

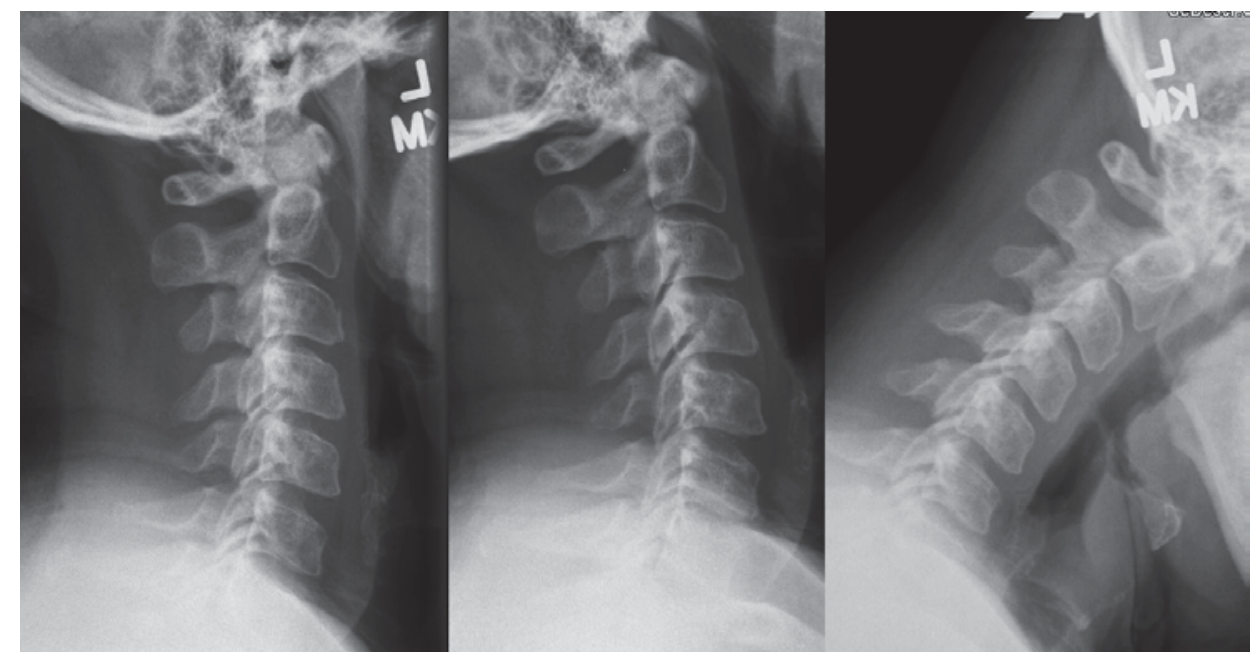

Fig. 3. Plain films of the cervical spine in neutral, extension, and flexion positions.

\subsection{Kinematics of the cervical spine}

The kinematics of the cervical spine are well established. In one classic study, the range of motion of 150 asymptomatic adults of both genders was determined using a threedimensional motion measuring device. Each subject was seated in a chair that immobilized the subcervical spine and then subjected to five passive motions: flexion/extension, lateral bending, axial rotation, axial rotation out of maximum flexion, and axial rotation out of maximum extension (table 1). On average, women had a greater range of motion than men. Overall, range of motion decreased with age. Evaluation of these motions is an important component in the examination of patients with suspected cervical injury (Dvorak et al., 1992). 


\begin{tabular}{|c|c|c|c|c|c|c|c|c|c|c|}
\hline Age & \multicolumn{2}{|c|}{$\begin{array}{c}\text { Flexion and } \\
\text { Extension }\end{array}$} & \multicolumn{2}{c|}{$\begin{array}{c}\text { Lateral } \\
\text { Bending }\end{array}$} & \multicolumn{2}{c|}{$\begin{array}{c}\text { Axial } \\
\text { Rotation }\end{array}$} & \multicolumn{2}{c|}{$\begin{array}{c}\text { Rotation } \\
\text { from Flexion }\end{array}$} & \multicolumn{2}{c|}{$\begin{array}{c}\text { Rotation } \\
\text { from } \\
\text { Extension }\end{array}$} \\
\hline & $\mathbf{M}$ & $\mathbf{F}$ & $\mathbf{M}$ & $\mathbf{F}$ & $\mathbf{M}$ & $\mathbf{F}$ & $\mathbf{M}$ & $\mathbf{F}$ & $\mathbf{M}$ & $\mathbf{F}$ \\
\hline $\mathbf{2 0 - 2 9}$ & 152.7 & 149.3 & 101.1 & 100.0 & 183.8 & 182.4 & 75.5 & 72.6 & 161.8 & 171.5 \\
\hline $\mathbf{3 0 - 3 9}$ & 141.1 & 155.9 & 94.7 & 106.3 & 175.1 & 186.0 & 66.0 & 74.6 & 158.4 & 165.8 \\
\hline $\mathbf{4 0 - 4 9}$ & 131.1 & 139.8 & 83.7 & 88.2 & 157.4 & 168.2 & 71.5 & 85.2 & 146.2 & 153.9 \\
\hline $\mathbf{5 0 - 5 9}$ & 136.3 & 126.9 & 88.3 & 76.1 & 166.2 & 151.9 & 77.7 & 85.6 & 145.8 & 132.4 \\
\hline $\mathbf{8} \mathbf{6 0}$ & 116.3 & 133.2 & 74.2 & 79.6 & 145.6 & 154.2 & 79.4 & 81.3 & 130.9 & 154.5 \\
\hline
\end{tabular}

Table 1. Kinematic measurements of the cervical spine by gender and age (Reproduced from Dvorak et al., 1992).

\subsection{Biomechanics of the atlanto-occipital joint}

Although the atlanto-occiptal joint contributes to flexion, extension, lateral bending, and rotation, cadaveric studies indicate that its principle motion is flexion and extension. This motion is primarily restricted by bony elements (Wolfla, 2006). Approximately 24.5 degrees of motion is possible in flexion and extension, with the majority of motion in the direction of extension (Panjabi et al., 1988). Flexion is ultimately restricted by contact between the odontoid process and the occiput, while extension may be limited by the tectorial membrane. However, some evidence suggests that the tectorial membrane is not involved in limiting extension, but that it may act to reduce spinal cord compression by the odontoid process (Tubbs et al., 2007). Rotation and lateral bending are both restricted by bony articulation points, tight alar ligaments, and the capsular ligaments, causing them to account for 2.5-7.2 and 3.5-5.5 degrees of motion in a single direction, respectively (Debernardi et al., 2011; Goel et al., 1988; Panjabi et al., 1988). In the horizontal plane, the instantaneous axis of rotation for the atlanto-axial joint is located in the anteromedial foramen magnum (Iai et al., 1993).

\subsection{Biomechanics of the atlanto-axial joint}

The atlanto-axial joint also contributes to flexion, extension, lateral bending, and rotation. However, its primary function has been demonstrated to be rotation. These motions are primarily restricted by ligamentous elements (Wolfla, 2006). In a cadaver, axial rotation in one direction can account for 23.3-38.9 degrees (Goel et al., 1988; Panjabi et al., 1988). Using radiographic studies of live patients, one group confirmed a 38 degree motion, accounting for $77 \%$ of the 49 degrees of axial rotation of the cervical spine. Rotation in C3-C7 accounted for an additional 15 degrees, while a 4 degree negative rotation in the atlanto-occipital joint accounted for the remainder of the motion. In other words, rotation of the atlanto-axial joint is accompanied by a smaller rotation of the atlanto-occipital joint in the opposite direction. The odontoid process acts as a pivot point for rotation, with the instantaneous axis of rotation located at the center of this process (Iai et al., 1993). The contralateral alar ligament is pulled tight during rotation, limiting motion. Thus the right alar ligament limits rotation to the left, and the left alar ligament limits rotation to the right (Dvorak \& Panjabi, 1987). Capsular joint ligaments also play an important role in limiting atlanto-axial rotation (Debernardi et al., 2011). The accessory atlantoaxial ligament also functions to check rotation. However, its contributions are of questionable significance in the presence of functional alar ligaments (Brolin \& Halldin, 2004). 
Flexion and extension of the atlanto-axial joint account for a total of 10.1-22.4 degrees of motion, with both directions accounting for about the same range of mobility (Goel et al., 1988; Panjabi et al., 1988). The transverse portion of the cruciate ligament holds the dens tight against the anterior arch of the atlas and limits flexion of the C1-C2 joint. Extension is limited by the bony articulation points, and possibly by the tectorial membrane. An in vivo radiographic study demonstrated that the instantaneous axis for flexion and extension of the atlanto-axial joint is on the posterior surface of the odontoid process, approximately halfway between the base and the tip (Dvorak et al., 1991).

Lateral bending accounts for 6.7-11 degrees of motion in one direction (Iai et al., 1993; Panjabi et al., 1988). As in the atlanto-occipital joint, the alar ligaments, bony articulation points, and capsular ligaments are responsible for maintaining lateral rigidity (Dvorak et al., 1988).

\section{Pathological destabilization}

The biomechanical properties of the CVJ can be disrupted by trauma, degenerative disease, neoplasm, infection, iatrogenic injury, and congenital defects. In this chapter, we focus on disruptions due to trauma, rheumatoid arthritis, and Down syndrome. .

\subsection{Traumatic alterations in biomechanics}

Trauma to the cervical spine typically occurs through high energy events such as falls, sports injuries, motor vehicle crashes, and diving accidents. CVJ instability should be suspected if there is weakness in the arms, dislocation, subluxation, or any of the radiographic findings listed in table 2 (White \& Panjabi, 1990). Destabilization can occur due to fractures of any of the bones and some of the supporting ligaments of the CVJ.

\begin{tabular}{|l|l|}
\hline$>8^{\circ}$ & Axial rotation C0-C1 to one side \\
\hline$>1 \mathrm{~mm}$ & C0-C1 translation (sagittal plane) \\
\hline$>7 \mathrm{~mm}$ & Overhang C1-C2 (total right and left) \\
\hline$>45^{\circ}$ & Axial rotation C1-C2 to one side \\
\hline$>4 \mathrm{~mm}$ & C1-C2 translation (sagittal plane) \\
\hline$<13 \mathrm{~mm}$ & Posterior body C2-posterior ring of C1 \\
\hline & Avulsed transverse ligament \\
\hline
\end{tabular}

Table 2. Criteria for CVJ instability (Reproduced from White \& Panjabi, 1990)

Although many occipital condyle fractures are asymptomatic, some have the potential to cause major CVJ destabilization. These fractures are classified as type I, type II, and type III fractures. Type I fractures occur from comminution of the occipital condyle without significant bone fragment displacement into the foramen magnum. Excessive axial loading is believed to be the biomechanical cause of these injuries. In rare cases the alar ligament may also be damaged to produce instability. However, a competent contralateral alar ligament and tectorial membrane are generally more than sufficient to maintain stability. Type II fractures occur when a linear fracture crosses over from the base of the skull with extension to the occipital condyle. These fractures remain attached to the base of the skull and are typically stable. Type III fractures occur from condylar avulsion due to excess force form lateral bending or axial rotation (Karam \& Traynelis, 
2010). The alar ligaments are often compromised in type III fracture, causing them to generally be considered unstable, and the condylar fragments can be displaced into the crowded foramen magnum, which can cause neurovascular injury (Anderson \& Montesano, 1988). Damage to the occipital condyle has been modelled in cadaveric studies with progressive, unilateral condylectomies. Hypermobility was noted in all of the motions of the atlanto-occipital joint (flexion, extension, axial rotation, and lateral bending) with a fifty percent resection of the condyle. In the atlanto-axial joint, hypermobility was achieved with $25 \%$ resection for flexion and extension, $75 \%$ resection for axial rotation, and $100 \%$ resection for lateral bending. Taken together, these results indicate that condylar injuries have great potential to disrupt the stability of the atlantooccipital joint (Vishteh et al., 1999).

Fractures of the atlas most commonly occur in the anterior or posterior arches. The Jefferson fracture, first characterized by Geoffrey Jefferson in 1919, is a lesion of both arches that has unique biomechanical significance (Jefferson, 1919). A classical Jefferson fracture is characterized by two fractures in each of the vertebral arches, resulting in four distinct bone fragments. However, significant variability exists, resulting in fractures with two to five fragments. This fracture can occur as the result of hyperextension of the neck causing a blow to the back of the head which transmits significant force to the CVJ. Alternatively, strong axial forces from an extraphysiological load-such as would occur in a dive into shallow water-cause axial loading on the skull which translates force to the cervical spine through the occipital condyles. This downward load causes the lateral masses of the atlas to spread apart, introducing strain and potential fracture into the thin anterior and posterior arches (Bozkus et al., 2001). In a cadaveric study of atlantal fractures, high-speed axial force produced fragmentation in the classical pattern described by Jefferson. These cervical segments also had significant destabilization, resulting in range of motion increases of $40 \%$ in flexion and extension, and 20\% in lateral bending (Panjabi et al., 1991b). The axial loading that causes Jefferson fractures is also implicated in the genesis of transverse ligament damage, and the identification of a coexisting ligament injury is of utmost clinical importance. These two pathologies often coexist, causing significantly increased cervical destabilization. The biomechanical changes associated with transverse ligament damage are explained below.

The axis is susceptible to three categories of fractures: fractures of the odontoid process, fractures of the pars interarticularis, and fractures of the axis body. Fractures of the odontoid process and pars interarticularis are the most common, and have the largest effects on CVJ instability.

Fractures of the odontoid process are the most common traumatic lesion of the axis. These are categorized by the location of the fracture, and occur near the tip of the odontoid process (type I), at the junction between the body and the odontoid process (type II), or within the body of the axis (type III). Of these, type II fractures are the most common and the most unstable. One finite element model of type II odontoid fractures suggests that a combination of lateral force and axial rotation are responsible for this fracture. Lateral force causes displacement of the first two vertebrae and places the inferior articular process of the atlas on the odontoid process. Axial rotation in turn puts tension on the alar ligament, placing torque on the dens. These two forces together contribute to fracture and potential displacement of bone into the spinal canal (Puttlitz et al., 2000). 
Damage to the pars interarticularis of the axis is referred to as Hangman's fracture or traumatic spondylolisthesis of the axis. The name Hangman's fracture has its origins due tothe similarities these axial fractures have to lesions reported in judicial hangings (Rayes et al., 2011). Although once widely believed to contribute to death in many hangings, a study of cervical vertebrae from 34 judicial hanging victims revealed only 6 axial fractures, of which only 3 were Hangman's fractures (James \& Nasmyth-Jones, 1992). However, the biomechanical mechanism of injury is clear. In a judicial hanging, the submental knot pulls upward on the jaw, jerking the head backwards in relation to the neck. The more extensible atlanto-occipital joint is not affected by this movement and the hanging body causes distraction and extension of the subaxial spine. This causes the atlanto-axial joint to undergo abrupt hyperextension, causing compression and fracture in the pars interarticularis. Today, hangman's fracture is most commonly seen in head-on collisions between automobiles. When a car crashes, the head continues forward relative to the restrained body. This motion, however, cannot explain the hangman's fracture. When modelled in primates, this form of trauma resulted in antlanto-occipital dislocation, but never axial fracture. The more likely explanation for the hangman's fracture is rapid backwards deceleration of the head from contact with the steering wheel or dashboard. This results in compressive hyperextension that affects only the craniovertebral junction, causing the axis to fracture (Penning, 1995).

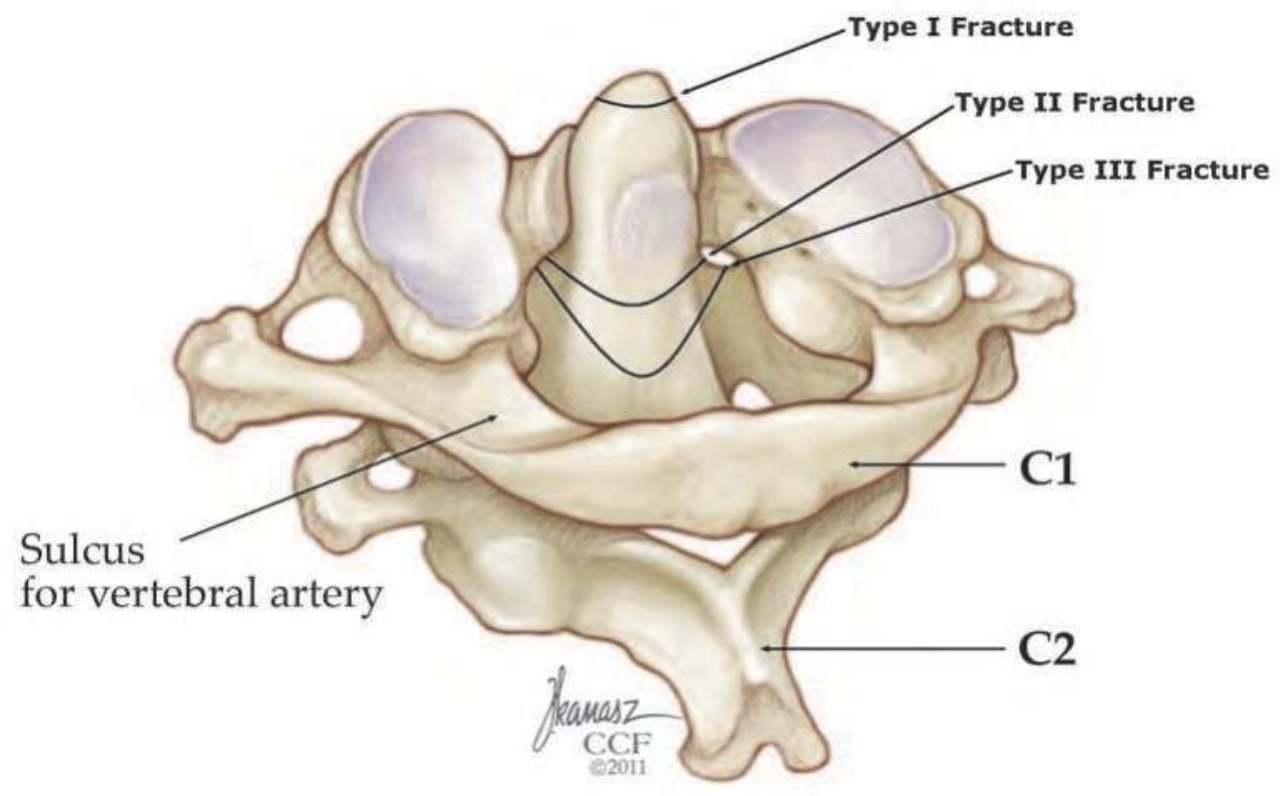

Fig. 4. Fractures of the odontoid process. 
Of all axial lesions, the biomechanics of surgically-induced transoral odontoidectomy may be the best understood. This procedure is normally used to treat cervicomedullary compression. In a study of cadaveric human spines, transoral odontoidectomy was found to significantly increase translational motion from less than one millimeter in all directions to 10.2, 6.7, and 2.0 millimeters in the anterior-posterior, lateral, and superiorinferior directions, respectively. Surprisingly, axial rotation had no quantitative change. However, lateral bending, flexion, and extension increased by $95 \%, 71 \%$, and $104 \%$, respectively. Each of these changes was principally due to expansion of the neutral zone (Dickman et al., 1995).

Damage to the transverse ligament can occur in isolation, but it usually accompanies damage to other regions of the CVJ, especially fractures of the atlas. Likewise, associated damage to the alar and apical ligaments is also common. The transverse ligament is susceptible to midsubstance tearing, or it can be disrupted by avulsion from the lateral mass of the atlas. In one study, axial loading was shown to cause damage to the transverse ligament, both with and without fractures of the atlas (Panjabi et al., 1991b). Other reports suggest that neck flexion can also cause transverse ligament disruption (Jackson et al., 2002). This explains why head-on collisions are more likely to result in transverse ligament injury than rear-end crashes (Debernardi et al., 2011). Experimental damage to the transverse ligament produces biomechanical instability that is similar to iatrogenic odontoidectomy, resulting in substantially increased translational motion, lateral bending, flexion, and extension (Saldinger et al., 1990).

The alar ligament is most susceptible to injury in rear-end collisions. In this situation, a sudden, unexpected collision of a slightly rotated head induces maximal rotation and whiplash flexion. Since the limitation of axial rotation is the most important function of the alar ligament, this pathological motion produces overstretch and potential rupture (Saldinger, 1990). In cadaveric models, unilateral transection of the alar ligament produced a small increase in axial rotation in the atlanto-axial joint. However, bilateral transection was linked to significant increases in axial rotation, flexion, extension, and lateral bending (Panjabi et al., 1991a).

\subsection{Biomechanical implications of rheumatoid arthritis and down syndrome}

In the absence of trauma or surgery, the craniovertebral junction tends to remain stable over time. Some congenital conditions can cause CVJ instability and some degenerative conditions, such as osteoporosis, do make the CVJ much more susceptible to fracture with age. Two of the most significant disorders that contribute to CVJ instability are rheumatoid arthritis and Downs syndrome.

Severe rheumatoid arthritis can cause erosion of the bony components of the CVJ. In particular, these degenerative changes can affect the insertions of the transverse ligament into the atlas, causing ligamentous laxity and atlanto-axial instability in $20-86 \%$ of patients with rheumatoid arthritis (Krauss et al., 2010). These osteoarthropathies may contribute further instability as they progress to include disruption of the alar ligament, the occipital condyles and the odontoid process. This condition, known as basilar impression, is hallmarked by translation of the odontoid process in the cranial direction and subluxation or dislocation of the atlanto-occipital joint (Martin et al., 2010). Additionally, an odontoid pannus often develops, which has the potential to compress the spinal cord (Krauss et al., 2010). A recent study using computed tomography (CT) of patients with rheumatoid 
arthritis in the cervical spine reported instability in sagittal translation in a large percentage of patients. In this study, 8 of 24 patients had occipital condyle deformity, while 15 of 24 had lesions in one or more lateral masses of the axis. Damage to the condyles caused the atlantooccipital joint to undergo translation in the posterior direction during flexion. In contrast, deformity in the lateral masses caused the atlanto-axial joint caused translation in the anterior and inferior directions during flexion. These movements contribute to pathological instability that should be considered when working with rheumatoid arthritis patients (Takatori et al., 2010).

Down syndrome is a relatively common genetic disease which is associated with craniocervical instability. Although the majority of these cases are asymptomatic, radiographic screening is still recommended before competition in athletic events like the Special Olympics. Instability can be due to abnormalities in either the atlanto-occipital or atlanto-axial junction (Hankinson \& Anderson, 2010). Two main hypotheses have been proposed to explain the instability of the atlanto-axial joint. First, the occipital condyles and the superior articular processes of the atlas remain flatter than in children without Down syndrome. CT data clearly suggests that the flattened surfaces of these condyles become more rounded as children age. In principle, this abnormal bone formation fails to restrict the lateral and anterior motions of the atlanto-axial joint, resulting in instability (Browd et al., $2006,2008)$. The second theory suggests that ligamentous laxity is the principle cause of instability in these patients. However, it is currently unknown which of these two theories explains the majority of the effect. Instability of the atlanto-axial joint is generally due to a loose articulation between the odontoid process and the anterior arch of the atlas. This results in marked instability in rotation, flexion, and extension. The cause of this instability is probably due to a combination of factors. These may include disconnection of the odontoid process from the body of the axis (os odontoideum) and ligamentous laxity due to collagen defects and chronic inflammation. Proper management of these instabilities is essential before these patients compete in contact sports or organized, strenuous events (Hankinson \& Anderson, 2010).

\section{General biomechanical principles of fixation}

The complex anatomy of the CVJ introduces significant challenges to appropriate fixation. Fortunately, many of the fractures of the cervical spine can be treated nonsurgically with orthosis alone. However, multiple fractures, fracture displacement, instability and neurological compression are all factors that can require surgical intervention. Although a thorough treatment of CVJ fixation is beyond the scope of this chapter, it is important that certain principles of fixation be understood when considering proper surgical fixation of the CVJ.

Fixation to the occiput is best accomplished through the use of screws and rods/plates. In pull-out experiments, bicortical screws resisted $50 \%$ more force than unicortical screws or wires. The most stable location for screw placements was within the midline keel of the occiput (Haher et al., 1999). The thickness of the occipital protuberance decreases significantly in the lateral and caudal bone. Therefore, screws placed at or just lateral to the keel have the most pullout resistance. In one cadaveric study, constructs utilizing screws placed in the lateral occiput were found to better resist lateral bending, while screws placed more medially were better for resisting axial rotation. These considerations make the 
evaluation of individual patient characteristics vital in the selection of fixation technique (Anderson et al., 2006; Steinmetz et al., 2010).

The atlas can be a challenging site for fixation, especially when it is disrupted by CVJ pathology. Although the lateral masses can accept sublaminar wiring, lateral mass screws withstand greater pullout forces. Bicortical placement should also be utilized, as it also appears to enhance pullout resistance (Steinmetz et al., 2010). However, caution should be used when using bicortical screws, as the internal carotid artery can be at risk for puncture in a subset of patients (Currier et al., 2008). Another successful approach has been to place screws that penetrate both the posterior arch and the lateral mass (Tan et al., 2003).

Fixation to the axis can be accomplished through sublaminar wiring, or through screws placed in the pedicle or lamina. Alternatively, screws may be placed transarticularly, allowing them to span both the atlas and the axis (Steinmetz et al., 2010).

Once a plan has been made to place screws, wires, rods or plates, constructs and longitudinal members must be developed to stabilize the CVJ. Since the atlanto-axial joint is responsible for the axial rotation, stabilization of pathological rotation can be accomplished by fixation of the atlas to the axis. This is best accomplished through transarticular screws (Oda et al., 1999). A screw that goes through the lateral mass of the atlas and then through the axis can also be effective, although this method has been shown to provide significantly less stiffness (Finn et al., 2008). Although the principle motion of the atlanto-occipital joint is flexion and extension, stabilization of this motion cannot be adequately prevented with fixation of the occiput to the atlas. However, fixation of the occiput to the axis can produce optimal stabilization of aberrant flexion and extension (Hurlbert et al., 1999; Steinmetz et al., 2010).

\section{Conclusions}

The craniovertebral junction is an intricate structure with unique anatomy and complex biomechanical characteristics. These characteristics allow for significant flexion, extension, and axial rotation with remarkable stability under normal circumstances. However, trauma, degenerative disease, and some congenital disorders can cause instability in this region. A thorough understanding of the biomechanics of the CVJ is necessary to design strategies to stabilize the pathologies of the upper cervical spine.

\section{References}

Anderson, P., \& Montesano, P. (1988). Morphology and Treatment of Occipital Condyle Fractures. Spine, Vol.13, No.7, (July 1988), pp. 731-736, ISSN 1528-1159

Anderson, P., Oza, A., Puschak, T., \& Sasso, R. (2006). Biomechanics of Occipitocervical Fixation. Spine, Vol.31, No.7, (April 2006), pp. 755-761, ISSN 1528-1159

Bozkus, H., Karakas, A., Hancı, M., Uzan, M., Bozdag, E., \& Sarıoglu, A., (2001). Finite Element Model of the Jefferson Fracture: Comparison with a Cadaver Model. European Spine Journal, Vol.10, No.3, (June 2001), pp. 257-263, ISSN 09406719 
Brolin, K., \& Halldin, P. (2004). Development of a Finite Element Model of the Upper Cervical Spine and a Parameter Study of Ligament Characteristics. Spine, Vol.29, No.4, (February 2004), pp. 376-385, ISSN 1528-1159

Browd, S., Healy, L., Dobie, G., Johnson, J., Jones, G., Rodriguez, L., \& Brockmeyer, D. (2006). Morphometric and qualitative analysis of congenital occipitocervical instability in children: implications for patients with Down syndrome. Journal of Neurosurgery: Pediatrics, Vol.105, No.1, (July 2006), pp. 50-54, ISSN 1933-0715

Browd, S., McIntyre, J., \& Brockmeyer, D. (2008). Failed age-dependent maturation of the occipital condyle in patients with congenital occipitoatlantal instability and Down syndrome: a preliminary analysis. Journal of Neurosurgery: Pediatrics, Vol.2, No.5, (November 2008), pp. 359-364, ISSN 1933-0715

Currier, B., Maus, T., Larson, D., \& Yaszemski, M. (2008). Relationship of the internal carotid artery to the anterior aspect of the C1 vertebra: implications for C1-C2 transarticular and C1 lateral mass fixation. Spine, Vol.33, No.6, (March 2008), pp. 635-639, ISSN 1528-1159

Debernardi, A., D’ Aliberti, G., Talamonti, G., Villa, F., Piparo, M., \& Collice, M. (2011). The Craniovertebral Junction Area and the Role of the Ligaments and Membranes. Neurosurgery, Vol.68, No.2, (February 2011), pp. 291-301, ISSN 0148-396X

Dickman, C., Crawford, N., Brantley, A., \& Sonntag, V. (1995). Biomechanical effects of transoral odontoidectomy. Neurosurgery, Vol.36, No.6, (June 1995), pp. 1146-1152, ISSN 0148-396X

Dvorak, J., \& Panjabi, M. (1987). Functional anatomy of the alar ligaments. Spine, Vo.12, No.2, (March 1987), pp. 183-189, ISSN 1528-1159

Dvorak, J., Schneider, E., Saldinger, P., \& Rahn, B. (1988). Biomechanics of the craniocervical region: The alar and transverse ligaments. Journal of Orthopaedic Research, Vol.6, No.3, (May 1988), pp. 452-461 ISSN 0736-0266

Dvorak, J., Panjabi, M., Novotny, J., \& Antinnes, J. (1991). In vivo flexion/extension of the normal cervical spine. Journal of Orthopaedic Research, Vol.9, No.6, (November 1991), pp. 828-834, ISSN 0736-0266

Dvorak, J., Antinnes, J., Panjabi, M., Loustalot, D., \& Bonomo, M. (1992). Age and gender related normal motion of the cervical spine. Spine, Vol.17, No.10 Supplement, (October 1992), pp. S393-S398, ISSN 1528-1159

Finn, M., Fassett, D., Mccall, T., Clark, R., Dailey, A., \& Brodke, D. (2008). The cervical end of an occipitocervical fusion: a biomechanical evaluation of 3 constructs. Journal of Neurosurgery: Spine, Vol.9, No.3, (September 2008), pp. 296-300, ISSN 1547-5654Gehweiler, J., Daffner, R., \& Roberts, L. (1983). Malformations of the atlas vertebra simulating the Jefferson fracture. American Journal of Roentgenology, Vol.140, No.6, (June 1983), pp. 1083-1086, ISSN 15463141

Goel, V., Clark, C., Gallaes, K., \& Liu, Y. (1988). Moment-Rotation relationships of the ligamentous occipito-atlanto-axial complex. Journal of Biomechanics, Vol.21, No.8, (August 1990), pp. 673-680, ISSN 0021-9290 
Haher, T., Yeung, A., Caruso, S., Merola, A., Shin, T., Zipnick, R., Gorup, J., et al. (1999). Occipital Screw Pullout Strength: A Biomechanical Investigation of Occipital Morphology. Spine, Vol.24, No.1, (January 1999), pp. 5-9, ISSN 1528-1159

Hankinson, T., \& Anderson, R. (2010). Craniovertebral junction abnormalities in Down syndrome. Neurosurgery, Vol.66, No.3 Supplement, (March 2010), pp. 32-38, ISSN 0148-396X

Hurlbert, R., Crawford, N., Choi, W., \& Dickman, C. (1999). A biomechanical evaluation of occipitocervical instrumentation: screw compared with wire fixation. Journal of Neurosurgery: Spine, Vol.90, No.1 Supplement, (January 1999), pp. 84-90. ISSN 15475654

Iai, H., Moriya, H., Goto, S., Takahashi, K., \& Tamaki, T. (1993). Three-dimensional motion analysis of the upper cervical spine during axial rotation. Spine, Vol.18, No.16, (December 1993), pp. 2388-2392 ISSN 1528-1159

Jackson, R., Banit, D., Rhyne, A., \& Darden, B. (2002). Upper cervical spine injuries. Journal of the American Academy of Orthopedic Surgeons, Vol.10, No.4, (July-August 2002), pp. 271-280 ISSN 1067-151X

James, R., \& Nasmyth-Jones, R. (1992). The occurrence of cervical fractures in victims of judicial hanging. Forensic Science International, Vol.54, No.1, (April 1992), pp. 81-91, ISSN 0379-0738

Jefferson, G. (1919). Fracture of the atlas vertebra. Report of four cases, and a review of those previously recorded. British Journal of Surgery, Vol.7, No27, (1919), pp. 407-422, ISSN 1365-2168

Karam, Y., \& Traynelis, VC. (2010). Occipital condyle fractures. Neurosurgery, Vol.66, No.3 Supplement, (March 2010), pp. A56-A59, ISSN 0148-396X

Krauss, W., Bledsoe, J., Clarke, M., Nottmeier, E., \& Pichelmann, M. (2010). Rheumatoid Arthritis of the Craniovertebral Junction. Neurosurgery, Vol.66, No.3 Supplement, (March 2010), pp. A83-A95, ISSN 0148-396X

Martin, M., Bruner, H., \& Maiman, D. (2010). Anatomic and Biomechanical Considerations of the Craniovertebral Junction. Neurosurgery, Vol.66, No.3 Supplement, (March 2010), pp. A2-A6, ISSN 0148-396X

Menezes, A., \& Traynelis, V. (2008). Anatomy and biomechanics of normal craniovertebral junction (a) and biomechanics of stabilization (b). Child's Nervous System, Vol.24, No.10, (October 2008), pp. 1091-1100, ISSN 1433-0350

Oda, I., Abumi, K., Sell, L., Haggerty, C., Cunningham, B., \& McAfee, P. (1999). Biomechanical Evaluation of Five Different Occipito-Atlanto-Axial Fixation Techniques. Spine, Vol.24, No.22, (November 1999), pp. 2377-2382, ISSN 15281159

Panjabi, M., Dvorak J., Duranceau, J, Yamamoto, I., Gerber, M., Rauschning, W., \& Bueff H. (1988). Three-Dimensional Movements of the Upper Cervical Spine. Spine, Vol.13, No.7, (July 1988), pp. 726-730, ISSN 1528-1159

Panjabi, M, Dvorak, J, Crisco, J., Oda, T, Wang, P., \& Grob, D. (1991). Effects of alar ligament transection on upper cervical spine rotation. Journal of Orthopaedic Research, Vol.9, No.4, (July 1991), pp. 584-593, ISSN 0736-0266 
Panjabi, M, Oda, T, Crisco, J, Oxland, T., Katz, L., \& Nolte, L. (1991). Experimental Study of Atlas Injuries I: Biomechanical Analysis of Their Mechanisms and Fracture Patterns. Spine, Vol.16, No.10 Supplement, (October 1991), pp. S460-S465, ISSN 1528-1159

Panjabi, M., Oxland, T., \& Parks, E. (1991). Quantitative anatomy of cervical spine ligaments. Part I. Upper cervical spine. Journal of Spinal Disorders, Vol.4, No.3, (September 1991), pp. 270-276, ISSN 0895-0385

Penning, L. (1995). Kinematics of cervical spine injury. A functional radiological hypothesis. European Spine Journal, Vol.4, No.2, (April 1995), pp. 126-132, ISSN 1432-0932

Puttlitz, C., Goel, V., Clark, C., \& Traynelis, V. (2000). Pathomechanics of Failures of the Odontoid. Spine, Vol.25, No.22, (November 2000), pp. 2868-2876, ISSN 15281159

Rayes, M., Mittal, M., Rengachary, S., \& Mittal, S. (2011). Hangman's fracture: a historical and biomechanical perspective. Journal of Neurosurgery: Spine, Vol.14, No.2, (February 2011), pp. 198-208, ISSN 1547-5654

Saldinger, P., Dvorak, J., Rahn, B., \& Perren, S., (1990). Histology of the Alar and Transverse Ligaments. Spine, Vol.15, No.4, (April 1990), pp. 257-261, ISSN 15281159

Steinmetz, M. P., Mroz, T. E., \& Benzel, E. (2010). Craniovertebral Junction: Biomechanical Considerations. Neurosurgery, Vol.66, No.3 Supplement, (March 2010), pp. A7-A12, ISSN 0148-396X

Swartz, E., Floyd, R., \& Cendoma, M. (2005). Cervical spine functional anatomy and the biomechanics of injury due to compressive loading. Journal of Athletic Training, Vol.40, No.3, (July-September 2005), pp. 155-161, ISSN 1062-6050

Takatori, R., Tokunaga, D., Hase, H., Mikami, Y., Ikeda, T., Harada, T., Imai, K. (2010). Three-dimensional morphology and kinematics of the craniovertebral junction in rheumatoid arthritis. Spine, Vol.35, No.23, (November 2010), pp. E1278-1284, ISSN 1528-1159

Tan, M., Wang, H., Wang, Y., Zhang, G., Yi, P., Li, Z., Wei, H. (2003). Morphometric evaluation of screw fixation in atlas via posterior arch and lateral mass. Spine, Vol.28, No.9, (May 2003), pp. 888-895, ISSN 1528-1159

Tubbs, R., Grabb, P., Spooner, A., Wilson, W., \& Oakes, W. (2000). The apical ligament: anatomy and functional significance. Journal of Neurosurgery: Spine, Vol.92, No.2 Supplement, (April 2000), pp. 197-200, ISSN 1547-5654

Tubbs, R., Salter, E., \& Oakes, W. (2004). The Accessory Atlantoaxial Ligament. Neurosurgery, Vol.55, No.2, (August 2004), pp. 400-404, ISSN 0148-396X

Tubbs, R., Kelly, D., Humphrey, E., Chua, G., Shoja, M., Salter, E., Acakpo-Satchivi, L. (2007). The tectorial membrane: Anatomical, biomechanical, and histological analysis. Clinical Anatomy, Vol.20, No.4, (May 2007), pp. 382-386, ISSN 10982353

Vishteh, A., Crawford, N., Melton, M., Spetzler, R., Sonntag, V., \& Dickman, CA. (1999). Stability of the craniovertebral junction after unilateral occipital condyle resection: a biomechanical study. Journal of Neurosurgery: Spine, Vol.90, No.1 Supplement, (January 1999), pp. 91-98, ISSN 1547-5654 
White, A., \& Panjabi, M. (1990). Clinical Biomechanics of the Spine (Second Edition), J.B. Lippincott Company, 0-397-50720-8, Philadelphia, Pennsylvania

Wolfla, C. (2006). Anatomical, biomechanical, and practical considerations in posterior occipitocervical instrumentation. The Spine Journal, Vol.6, No.1 Supplement, (November-December 2006), pp. S225-S232, ISSN 1529-9430 


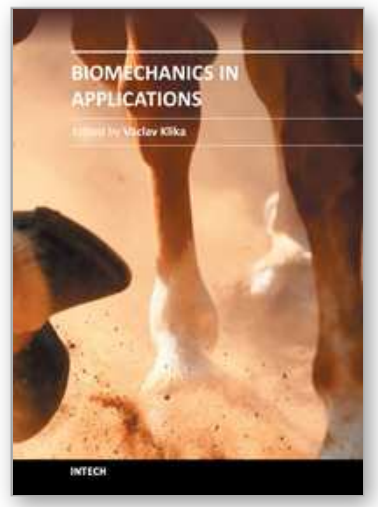

\author{
Biomechanics in Applications \\ Edited by Dr Vaclav Klika
}

ISBN 978-953-307-969-1

Hard cover, 408 pages

Publisher InTech

Published online 09, September, 2011

Published in print edition September, 2011

During last couple of years there has been an increasing recognition that problems arising in biology or related to medicine really need a multidisciplinary approach. For this reason some special branches of both applied theoretical physics and mathematics have recently emerged such as biomechanics, mechanobiology, mathematical biology, biothermodynamics. The Biomechanics in Application is focusing on experimental praxis and clinical findings. The first section is devoted to Injury and clinical biomechanics including overview of the biomechanics of musculoskeletal injury, distraction osteogenesis in mandible, or consequences of drilling. The next section is on Spine biomechanics with biomechanical models for upper limb after spinal cord injury and an animal model looking at changes occurring as a consequence of spinal cord injury. Section Musculoskeletal Biomechanics includes the chapter which is devoted to dynamical stability of lumbo-pelvi-femoral complex which involves analysis of relationship among appropriate anatomical structures in this region. The fourth section is on Human and Animal Biomechanics with contributions from foot biomechanics and chewing rhythms in mammals, or adaptations of bats. The last section, Sport Biomechanics, is discussing various measurement techniques for assessment and analysis of movement and two applications in swimming.

\title{
How to reference
}

In order to correctly reference this scholarly work, feel free to copy and paste the following:

Jeffrey G. Clark, Kalil G. Abdullah, Thomas E. Mroz and Michael P. Steinmetz (2011). Biomechanics of the Craniovertebral Junction, Biomechanics in Applications, Dr Vaclav Klika (Ed.), ISBN: 978-953-307-969-1, InTech, Available from: http://www.intechopen.com/books/biomechanics-in-applications/biomechanics-of-thecraniovertebral-junction

\section{INTECH}

open science | open minds

\section{InTech Europe}

University Campus STeP Ri

Slavka Krautzeka 83/A

51000 Rijeka, Croatia

Phone: +385 (51) 770447

Fax: +385 (51) 686166

www.intechopen.com

\section{InTech China}

Unit 405, Office Block, Hotel Equatorial Shanghai

No.65, Yan An Road (West), Shanghai, 200040, China 中国上海市延安西路65号上海国际贵都大饭店办公楼 405 单元

Phone: +86-21-62489820

Fax: $+86-21-62489821$ 
(C) 2011 The Author(s). Licensee IntechOpen. This chapter is distributed under the terms of the Creative Commons Attribution-NonCommercialShareAlike-3.0 License, which permits use, distribution and reproduction for non-commercial purposes, provided the original is properly cited and derivative works building on this content are distributed under the same license. 